\title{
Future role aspirations, achievement motivations and perceptions of personal help-seeking among humanitarian aid trainees
}

\author{
Kelsey Skeoch ${ }^{1}$, Garry J Stevens ${ }^{1 *}$ (i) and Melanie Taylor ${ }^{2,1}$
}

\begin{abstract}
Humanitarian aid workers experience adverse mental health effects from their work at higher rates than the military, police and other emergency service personnel. Whilst there is considerable literature investigating risk and resilience factors for workers within this field, little is known about the status of such factors among individuals prior to their joining the profession. Semi-structured interviews were conducted with ten commencing undergraduates of a Bachelor of Humanitarian and Development Studies course to explore their aspirations and resilience factors regarding future work. Thematic analysis identified that whilst there was a high level of reported altruism among trainees, these perceptions appeared to constrain individual use of social support networks and help-seeking behaviours. Education and training appeared to shift future work preferences from humanitarian relief work towards development-related roles. The findings suggest that humanitarian aid trainees exhibit known risk and resilience factors before they enter the profession, whilst highlighting practice expectations and personal support perceptions that are amenable to positive change through training.
\end{abstract}

Keywords: Humanitarian aid workers, Mental health, Training, Social support, Help-seeking, Risk, Resilience

Humanitarian aid (HA) work can be a compelling vocational area and typically attracts highly motivated individuals (Eriksson et al. 2012). However, the past two decades have seen these workers subject to more intractable response scenarios, including aid delivery in conflict and complex emergency settings. Workers are increasingly targeted for political purposes, and experiencing assaults and more direct threats to their lives (Quevillon et al. 2016). In 2015, $287 \mathrm{hu}$ manitarian aid (HA) workers were victims of major attacks including shootings and assaults, of which 109 were killed, 110 wounded and 68 kidnapped (Humanitarian Outcomes 2016).

\footnotetext{
* Correspondence: g.stevens@westernsydney.edu.au

${ }^{1}$ Humanitarian and Development Research Initiative (HADRI), School of Social Sciences and Psychology, Western Sydney University, Penrith, NSW 2751,

Australia

Full list of author information is available at the end of the article
}

\section{Mental health comparisons between humanitarian aid and emergency service workers}

In comparison to the general population, international expatriate and local national HA workers experience elevated levels of trauma and significantly higher rates of posttraumatic stress disorder (PTSD), depression, and anxiety (Connorton et al. 2012). A post-deployment survey of 376 national Ugandan HA workers (Ager et al. 2012) working locally in high conflict areas, and across 21 organisations, found $68 \%$ of respondents scored at or above established cut-offs on validated measures of depression and anxiety (The Hopkins Symptom Checklist, Derogatis et al. 1974), whilst $26 \%$ reported clinically significant symptoms on the Los Angeles Symptom Checklist for PTSD (King et al. 1995; Ager et al. 2012).

Aid workers also appear to experience occupational mental health effects at a higher rate than other professions exposed to potentially traumatising events. Studies of PTSD among military and police personnel have found prevalence estimates of $8.3 \%$ (Defence Health 2016) and 
10-12\% (Rose et al. 2002) for these populations respectively, compared with $4-6 \%$ of the general population (Cooper et al. 2014). Whilst studies of HA workers have generally relied on questionnaire measures rather than structured clinical interviews (producing estimates of "probable PTSD" rather than formal diagnoses), indicative rate estimates for PTSD among national and international expatriate HA workers range between 17 and $30 \%$ in the available literature (Eriksson et al. 2001; Armagan et al. 2006; Putman et al. 2009; Zhen et al. 2012).

\section{Disparities in training protocols}

Distinct differences in training protocols between HA workers and other professions exposed to potentially traumatising events have been identified as a key factor underpinning differences in mental health outcomes between these populations (Burke and Shakespeare-Finch 2011). Review of the available HA literature indicates that predeployment training varies widely among organisations; it frequently involves international agencies training expatriate workers and is often very limited in nature (Connorton et al. 2012; Ehrenreich and Elliott 2004; McCall and Salama 1999). Whilst these studies present a fairly bleak view of HA worker training, the broad picture is suspected to be worse. Connorton et al. (2012) argue that as participation in the surveys was voluntary, it is possible that agencies where training is perceived to be adequate were more likely to have returned surveys, thereby affecting the findings.

Inadequate training leaves workers with underdeveloped knowledge and skills, including potentially unrealistic expectations of roles and achievements. These factors may predispose them to adverse mental health outcomes including depression, anxiety, occupational burnout and PTSD (Mollica et al. 2004; Cardozo et al. 2005; Dahlgren et al. 2009). Conversely, training that specifically targets the risk and resilience profile of those who choose a profession is thought to produce workers who are more resilient to career challenges, thereby reducing the risk of adverse mental health outcomes (Burke and Shakespeare-Finch 2011). For example, it has been found that police officers often cope well with potentially traumatising events. One explanation for this is that their training regimes have prepared them in advance for such exposures (Chan et al. 2003; Gist and Woodall 2000). Evidence of the health benefits of training has led the Australian Ambulance Service to provide comprehensive in-house training (Robinson 1993), which appears to equip workers with effective personal resources to mitigate the effect of stressful events, resulting in more effective trauma recovery and reduced sick leave (Van der Kolk and Fisler 1995).

\section{Risk and resilience factors}

Research addressing the risk profile of trainee HA workers is very limited. One study of agency-employed workers (Eriksson et al. 2012) found they commonly exhibit certain risk factors (e.g. avoidant coping styles) and resilience factors (high levels of social support), before they enter the field. A resilience factor is conceptualised as a trait or behaviour that is associated with a lower likelihood of adverse mental health outcomes or that reduces the negative impact of a potential risk factor after incident exposure (O'Connell et al. 2009). Conversely, a risk factor is defined as a trait or behaviour associated with an increased risk of future harm to the individual (Metcalfe et al. 2011). Greater literature regarding these factors exists in relation to HA workers with field experience. This provides some basis for understanding factors which will potentially affect future workers. A review of the area reveals three key factors which have the potential to support or undermine occupational wellbeing among HA workers and related groups. These include motivation/achievement, social support, and help-seeking.

\section{Motivation and achievement}

Individuals who seek employment within HA are often highly motivated to achieve a particular goal (Eriksson et al. 2012). Research has found that altruistic individuals with high intrinsic motivation (i.e. based on personal values and outcomes) demonstrate good resilience against adverse effects on mental health, including burnout (Moreno-Jiménez and Villodres 2010). An individual's expectancy of achievement can also mediate one's risk. Within occupational settings, the theory of met expectations indicates that the higher the congruence between an individual's expectations and the reality of their work, the greater satisfaction and adjustment one experiences (Wanous et al. 1992). This accords with previous research in occupational settings, which found that met expectations were associated with high job satisfaction, performance and longevity (Wanous et al. 1992). Conversely, when expectations are not met, levels of satisfaction and personal accomplishment decrease (Delgatty 2011; Lee 2008). Achievement expectations have not been specifically examined in HA worker populations, although related work has found that HA workers with high levels of motivation are less likely to suffer from burnout (Cardozo et al. 2012). Notably, however, Tassell (2009) found that a sub-group of workers with high, potentially unrealistic motivation ("obsessive passion") for this work were significantly more likely to experience burnout.

\section{Social support and help-seeking}

Social support represents an important protective factor against adverse mental health effects for the general population, as it appears to provide an effective buffer against stressful experiences (Ager et al. 2012; Brooks et al. 2015; 
Cardozo et al. 2012; Eriksson et al. 2012; Musa and Hamid 2008). Social support is defined as emotional and instrumental social interactions that provide an individual with actual assistance or a belief that such assistance is available (Thoits 2011; Hobfoll 1988). Past studies in the HA field have found that strong social support may significantly decrease the risk of adverse mental health consequences for workers (Cardozo et al. 2012). Specifically, social support appears to positively predict worker wellbeing, satisfaction (Brooks et al. 2015) and resilience (Eriksson et al. 2009), as well as mitigate against adverse mental health consequences including psychological distress, burnout (Brooks et al. 2015; Cardozo et al. 2012; Musa and Hamid 2008), PTSD and depression (Eriksson et al. 2012).

One suggested mechanism by which social support acts as a resilience factor is through encouraging helpseeking; an adaptive response which counteracts the negative effects of stressful life events (Gourash 1978). Despite these apparent benefits, individual willingness to seek help from both personal and professional sources is often quite low (Zartaloudi and Madianos 2010). Individual factors associated with reduced help-seeking include the perceived need for self-reliance (i.e. believing one should deal with their own problems), social image concerns and lack of knowledge of mental health treatment effectiveness (Staniford et al. 2009; Fischer and Turner 1970). Research with HA workers found that such attitudes are associated with poorer trauma recovery (Connorton et al. 2012).

\section{The present study}

The available literature examining occupational wellbeing within the HA field focuses almost exclusively on worker populations with experience in the field. Only one study (Eriksson et al. 2012) has examined a predeployment training population, who were existing employees of an aid organisation, rather than a novice training group per se. Research conducted early in HA training and prior to agency experience can improve our understanding of the profile of those who pursue HA work, and the status of potential risk factors that may mediate future exposures.

The current study adopted a qualitative methodology to examine, within a trainee population, known risk and resilience factors for humanitarian occupational stress, with the aim of addressing the following research questions.

1. What are the role aspirations and achievement motivations of commencing humanitarian aid trainees?

2. What is the reported availability, use, and preference regarding social support among trainees?

3. What are trainee attitudes towards help-seeking in the context of personal stress?

\section{Method}

\section{Participants and procedure}

All students in the 2016 cohort of the Humanitarian and Development Studies program at Western Sydney University, Australia, were invited to participate in the study via email and recruitment flyers. Twelve members of this cohort agreed to participate in the study with ten ultimately being interviewed. The final sample comprised six females and four males, reflecting the gender proportion (64\% female) of the cohort. Participants were aged between 18 and $33(M=20.80, \mathrm{SD}=4.92)$. The majority (90\%) had completed high school the previous year and most had previously undertaken paid (90\%) and volunteer (80\%) work. Half identified as Anglo background, with other identified backgrounds including Filipino, Indian, Vietnamese, Fijian and West African. Three participants spoke English as a second language, and half were learning a second language (French, Spanish and Mandarin). The remaining members of the student group who were not interviewed did not differ substantially to the study sample by gender (66\% female), age or highest previous education (83\% high school). All participants had completed the first 12 weeks of their 3-year degree and indicated that they intended to pursue humanitarian and/or development aid work upon completion of their degree.

A qualitative design utilising a thematic analysis was employed to collect and analyse data. Thematic analysis was considered an appropriate method of analysis as it permits an in-depth, rich exploration of individuals' experiences and perceptions of HA and any potential risk and resilience factors they may exhibit (Braun and Clarke 2006). Upon replying to the emailed recruitment flyer, all participants booked in an interview time with the researcher at Western Sydney University, where data were collected from participants via semi structured, face-toface interviews. Participants received a 50 Australian Dollar monetary reimbursement for their time and travel expenses. Interviews were conducted by the researcher and continued until the point of theoretical saturation, that is, where no new themes were emerging from the data set (Morse 1995; Sandelowski 1995). Ten interviews had been conducted at this point of saturation, resulting in a sample of ten. Participants were de-identified at the point of manual transcription conducted by the principal author on a password-locked computers; all pseudonyms were used in any subsequent use of the data, including in this paper. In order to validate findings and ensure all themes were derived from the data, initial data coding was conducted by the author and a co-rater independently, before they came together to collate their findings.

\section{Measures}

The interview schedule was created by the authors through a series of pilot interviews with several lay 
individuals to ensure readability and understanding of concepts and question content. The schedule was used as the basis to guide the interview. The study was informed by a review of identified risk and resilience factors affecting professional aid worker health and wellbeing. This included such factors as perceived social support and attitudes towards personal help-seeking in the context of stress. The construction of some interview questions was also informed by a review of existing questionnaires (e.g. the Multidimensional Scale of Perceived Social Support, the Revised-COPE Scale and the Attitudes Towards Seeking Professional Psychological Help Scale (Zimet et al. 1988; Whittlesey 2001; Zuckerman and Gagne 2003)), with some items adapted where they captured themes relevant to the enquiries of this study.

Where no previous validated scale questions were available to address key areas of enquiry, questions were created based on findings in the current literature. For example, question 8, "People have different kinds of motivations for their work. How important is it for you to feel you have achieved an outcome that benefits others in the work that you do?" with the follow up question "Is there anything in particular you hope to achieve through this line of work?", is based on research that found unrealistic expectations of success, particularly when defined in terms of outcomes rather than effort, can often complicate recovery from trauma exposure (Barsalou 2008; McCammon et al. 1988). The interview schedule is available through the Western Sydney University's research repository (ResearchDirect).

\section{Analysis}

Thematic analysis (TA) was considered an appropriate method of analysis as it permits an in-depth, rich exploration of individuals' experiences and perceptions (Braun and Clarke 2006). TA following the procedure by Braun and Clarke (2006) was conducted to first organise and analyse the raw data in relation to the research questions. The analysis was inductive in nature as the identified themes were grounded in, and induced from, the data set. The process of TA began with the familiarisation of the data set (Braun and Clarke 2006), where data extracts of particular interest and related to the studies' aims were coded manually into categories by the researcher using Microsoft Word. These meaning units or categories of data were then named to form codes. Codes were then examined for similarities and differences and grouped together accordingly to create initial sub-themes representative of the data and research questions (Braun and Clarke 2006). Initial sub-themes were then analysed for any further relationships between each other and grouped together to generate overarching themes (Braun and Clarke 2006). This process involved constant checking against the original data set to ensure validity of themes (Braun and Clarke 2006). A further validity check was conducted through the use of a corater (Fereday and Muir-Cochrane 2006); a female psychologist with clinical experience, but without specific subject matter expertise regarding HA occupational health. This co-rater independently followed the same process outlined above for the entire data set. The corater and researcher then met to discuss similarities and differences among each of their independent findings. Agreement of findings was obtained through such discussion and collaborative mapping, resulting in four overarching themes that best represented the data set and research questions.

\section{Results}

Thematic analysis was used to identify patterns and commonalities across participant interviews regarding current experiences of social support, help-seeking attitudes and behaviours, and motivations and aspirations regarding HA work. Four major themes emerged regarding mental health risk and resilience factors for trainee HA workers in the current sample: (1) The goal of supporting people; (2) Humanitarian aid short-term, development long-term; (3) Social support based on likeness and (4) Help-seeking: a good idea that is not implemented. Interview excerpts have been selected based on their relevance and importance in illustrating emergent themes.

\section{The goal of supporting people}

Altruism and wanting to contribute to a "better world" was a prominent motivation for working in HA as all participants reported wanting to support others as their overriding motivation. This was illustrated in Kelly's account of wanting to work towards something bigger than herself, "I just want to help people...I don't care about getting money...all I want to know is that I am doing good for someone else". Similarly, Jim spoke of wanting to "restore balance" in an "unjust world". This sentiment was conveyed throughout interviews and often centred upon the thought that most participants felt lucky to be living relatively privileged lives. Thus, there was a strong expressed desire to provide support and opportunities to those experiencing hardship.

Whilst all participants identified something they wanted to achieve in their work, such as outcomes that benefited others, their definitions of success varied. The majority reported trying one's best as an important measure of success (8/10); however, some participants $(2 / 10)$ also noted external measures, such as outcomes defined by specific field guidelines (e.g. Sphere Handbook, Salama et al. 2001). All participants noted that not achieving particular outcomes would not deter them. Instead, in most cases it 
would make them want to work harder, utilising ingenuity and problem solving to achieve a particular goal.

It was common for participants to report wanting to support in ways that would enable communities to be better equipped for future disasters, by supporting community knowledge and resources (7/10). Jess exemplified this idea through reporting wanting to "Teach and educate communities...so that they are better prepared". She further highlighted this point by referencing a variant of a common saying "teach a man how to fish, rather than [just] giving him a fishing rod", suggesting that supporting self-reliance and preparedness is of greater longerterm value than material support in isolation. This highlights participants' developing philosophies regarding assistance provision, particularly in the development of community resources and disaster response capabilities.

\section{Humanitarian aid short-term, development long-term}

The majority of participants reported that they initially came into their studies with the idea of having a sustained career within HA field-based work (9/10). However, after initially learning about HA and what it entails, described by one participant as it is "in and out nature", more than half $(7 / 10)$ are now considering seeking experience in development based aid work. This was most commonly framed as seeking initial experience in HA before later moving into the area of development. Participants understood development as offering a more longterm role, where they could potentially be involved in more enduring change processes. Kelly's statement typified these evolving views:

Coming into the course that is what I wanted to do but as I'm learning about the nature of HA my ideas are changing...short-term I'd like to do [HA] field work and then long-term move towards development.

The idea of being able to make a more lasting and substantial change was one of the major reasons participants reported for wanting to move into development work. Not only did participants feel they would be able to make a "greater difference" (Allen), but they also felt being able to make changes at a policy level, which they felt was possible in development, would enable them to have a "... greater impact...on a much broader scale" (Chris).

The political nature of HA was also commonly mentioned by participants as being a deterrent to long-term work in HA (6/10). Participants noted that they were unsure as to whether they and their employing organisations would be fighting for the same goal. This made them feel uneasy, given their developing views on social justice:

That's one reason I'm sort of shifting towards development is because I'm reading so much about the...political side of aid work, it's sort of scary, like I thought these people were genuinely going to help and then you have all these other agendas and it's sort of like I don't know how it's going to go when I get there. (Kelly)

Thus, although this sample of participants report a strong desire to support others in need, their education on the topic has led them to reflect upon the extent to which they could work in humanitarian relief contexts on a sustained basis. Whilst the cross-sectional nature of this study means this perceived "shift" towards development roles must be treated with caution, it appears to show a developing sophistication regarding knowledge of the aid field and future role choices derived from their studies.

\section{Social support based on likeness}

Overall, all participants reported having good social support networks around them from family, friends and partners. However, all participants except for Kelly reported that they would be more likely to seek support from their friends than their family. This appeared to be the case as participants reported preferring to derive their support networks from others with whom they share more immediate similarities and understandings. For example, Chris reported that he feels as though he "...can talk with [his friends] about problems they can relate to..." whereas his family provides a more "...basic level of support".

In a similar vein, the idea of seeking support based on shared understandings and experiences appeared to be central to support considerations in future HA work settings. Almost all participants (9/10) indicated they would be more inclined to seek support from colleagues, or the organisation itself when working in the field rather than their usual support networks back home. This appeared to constitute a form of "anticipatory" social support from future work colleagues who would understand their needs and perhaps have insights that would provide specific and unique benefits. On this basis participants felt they could readily pursue such support, alongside sources within agencies:

I would [seek support] from colleagues as they are the closest and they know what's going on in the field (Jack).

Moreover, throughout the interviews, it became clear that it is the knowledge of having an available support network, rather than actual received support, that provides comfort for participants. For example, despite participants' reports of having social support networks, the extent to which they use them is often limited. As Amy stated, "I do not really talk to people but if I do need to talk, I know I can”. 


\section{Help-seeking: a good idea that is not implemented}

The majority participants regarded the personal act of seeking help at times of personal stress as a positive endeavour (8/10), although several also saw it as a somewhat courageous step to take. As Sally stated, at times it can be "...harder to reach out...seek help and admit weakness" than it is to internalise and try to deal with one's own problems. However, participants spoke about help-seeking in a very detached manner, such that they believed it was a good thing for others, but was not necessarily something they implemented into their own lives: "I think it depends on the person...I would try and [deal with problems] myself" (Allen).

When specifically asked whether participants had sought help if they had experienced a stressful or highly emotional issue in their lives, low rates of help-seeking were reported. Moreover, when specifically asked if they had sought help in relation to a particular event, two of ten participants reported that they sought help in such a difficult situation, with one noting professional help. Looking at the sample as a whole, when asked if they were to seek help for whatever reason, their most common source was from friends rather than family. Notably, just over half of participants stated that they would not seek further help from a professional even if a particularly difficult or highly stressful situation were to occur.

Whilst the majority of participants viewed seeking help positively and all reported wanting to help others, there was an apparent perceived need for self-reliance which resulted in the majority of participants stating they would not necessarily seek help themselves (9/10). For example, Anna first stated, "I just want to help people... I'm passionate about helping people", demonstrating not only her intense desire to help but also her openness to the idea of people seeking help. However, she later stated, "My problems aren't big enough to be dealt with externally". This apparent contradiction between participant's views and actions was common across interviews. Chris noted his greatest "satisfaction" would come from helping others, whilst also saying "I don't like reaching out extensively".

A number of reasons were noted for not seeking help, including believing one's problems were not big enough to warrant taking the step to seek the help of others. For example, Anna stated, "People have bigger problems than me, mine aren't big enough". Another commonly reported reason was that participants preferred to deal with things "on their own" as they did not want to "... overbear [their] support network" (Chris), as others are "...dealing with their own things" (Beth). These reports highlight how the need for perceived self-reliance in the current sample may restrain help-seeking behaviours. The preference to rely on oneself in difficult times due to such things as concerns of stigma and poor mental health literacy is commonly found to be a barrier to help-seeking, particularly in young adults such as the current sample (Gulliver et al. 2010). Whilst the current participants largely aspire to altruistic and "helper" roles, their comments may similarly reflect stigma concerns (or even self-stigma) about being a "helpee", that is, constructing personal help-seeking as a potential burden within their support network and therefore something that is best avoided.

Importantly, a perceived lack of experience or specific skills in eliciting help was also a common barrier to participants seeking help. For example, Anna highlighted that although she feels as though one should ask for help if they need it, she finds that she is being somewhat "hypocritical" as she states "...it's easy to say that for other people but I don't know how I would go about asking for help."

Additionally, it is interesting to note that whilst participants reported low help-seeking behaviours at the time of interview, it was common for participants to mention that they would be more likely to seek help in the field than they do in their current lives. Nine of ten participants noted they would seek help from colleagues when in the field if they were experiencing heightened stress. Five noted they may also seek further assistance from the organisation or professionals in the field:

I think in the aid working field...I'd be quicker to go to a psychologist or a GP or a mental health worker... because you do see, experience things that can cause post-traumatic stress disorder and I think being able to address that immediately would save me a lot of stress in the future. (Chris)

\section{Discussion}

Trainee humanitarian aid workers were found to exhibit risk and resilience factors for occupational stress in the field. That is, before entering the field, the trainee group displayed attributes, behaviours and perceptions that have previously been shown to mediate mental health sequelae among HA worker populations, notably anxiety, burnout and PTSD (Ager et al. 2012; Brooks et al. 2015; Comoretto et al. 2015; Eriksson et al. 2012). This study found that the four factors, motivation and achievement, evolving ideas of HA, social support, and help-seeking attitudes and behaviours, represent potential mediating factors among these trainees.

The demographic profile of the current undergraduate sample shows a group that is predominantly female, of Anglo background, without a current second language, and recent high school graduates. Whilst most individuals had completed previous paid and/or volunteer work, paid work was typically casual whilst volunteer work was of short duration. The limited nature of work 
and life experience of these trainees may constitute an experiential risk factor for such populations. Whilst these are preliminary findings, they highlight the potential benefit of training within undergraduate programs to address issues such as cultural competence, occupational health and wellbeing, and the importance of both social and organisational support.

The present study found that through training and increased knowledge of the field, intentions regarding the type and duration of future roles in HA may change significantly. The current participants had only just begun their training within a 3-year undergraduate degree. However, initial exposure to the "basic" concepts of HA work and what it entails caused many to re-think their initial goals of a sustained career in the HA profession. Through their increased knowledge of the sometimes difficult nature of the work, potential incongruence between personal and organisational goals and the perceived potential to have a greater impact in development work, the most frequent intention became to seek HA roles in the short-term "for experience" before pursuing roles in development programs for a more prolonged, sustainable career. Arguably, this finding indicates a form of resilience within this trainee sample. The ability to adapt to new information, including actively selecting work environments which better support personal and professional goals, may be an important determinant of occupational health and longevity within this field. Whilst further research is needed, the present study contributes a novel insight regarding the implications of HA education on the intentions of future workers.

With regard to social support, the current results supported Benkel et al. (2009) finding that individuals prefer to seek support from their friends before their families during times of personal stress. Trainees also preferred to derive support from friends, due to their greater shared understanding and common experiences. The desire for support networks based on shared experiences and understanding also appears central to consideration of potential future work roles and relationships. This suggests a potentially important resilience factor for these future workers, who envision that colleagues may act as reliable sources of information and emotional support. This prior readiness to rely on colleagues in difficult circumstances when in the field, due to their perceived shared understanding, may prove to be a valuable protective factor that can be further supported and extended upon through training.

If HA workers are likely to seek support from their colleagues in the first instance, it may prove beneficial to equip both workers and trainees with mental health knowledge and skills. Mental Health First Aid training has been shown to increase knowledge of mental illness and treatments and provide individuals with appropriate strategies to support others in need (Aakre et al. 2016; Jensen et al. 2016). Such training in workplace settings has been found to increase individual willingness to provide support to others, a greater likelihood of advising others to seek professional help, and improvement in the mental health of the those who underwent the training themselves (Kitchener and Jorm 2004). Providing HA workers with such knowledge and skills may support similar outcomes, including positive mediation of mental health responses to field exposures.

The present study also examined specific attitudes towards personal help-seeking. This is an area scarcely recognised in the current $\mathrm{HA}$ literature, despite the known mental health sequelae within this population. When looking at the broader research base on helpseeking and mental health, the present findings contrast previous research that found a positive relationship between help-seeking attitudes and actual help-seeking behaviour (Zartaloudi and Madianos 2012). Respondents in the current study reported strong intentions towards future help-seeking with work colleagues, in the context of distress, and perceptions that such actions would be beneficial. Whilst the translation of these help-seeking intentions to future behaviours remains unclear, evidence from experimental psychology shows that high intent and high perceived positive outcomes predict high levels of behavioural translation (Azjen 1991; Cooke and French 2008). Against this, however, is the finding that current positive perceptions of help seeking with friends generally do not translate to help seeking attempts in this population. As these findings are based upon different samples, however, it is difficult to compare. One explanation for this difference may relate to trainees' high motivation to support others. This high level of altruism and related self-image may indicate that participants are more likely to put others' needs ahead of their own and are therefore unwilling to be seen as needing support themselves. A similar phenomenon was observed in 911 workers in the USA who were found to be highly motivated by altruism, but unlikely to seek help for personal stress, seeing it as "just part of the job" (Shuler and Sypher 2000). Tassell (2009) found that HA workers with high altruism were vulnerable to disillusionment and more likely to experience burnout. The specific relationship between help-seeking intentions and behaviours in a HA work context requires further research. Arguably, however, education programs with trainees could highlight the potential benefits of appropriate help-seeking in occupational contexts.

Nonetheless, the finding that participants perceive field-based needs as qualitatively different from their current lives (i.e. potentially risking personal health and wellbeing) appears to legitimise help-seeking, including that from health professionals. Such statements must be 
viewed with caution, since behavioural intentions are not strongly predictive of future behaviours (Thirlaway and Upton 2009). Also, professional help may not be as readily available in the field as participants may perceive and a high "response effort" for such help could simply reinforce pre-deployment ideals of foregoing personal help-seeking for the sake of helping others. However, this is a notable finding in that it suggests mental health literacy related to this work role may provide the conditions under which help-seeking, in the context of heightened stress, would be viewed as being "acceptable". Whilst further research is needed regarding this relationship, this finding highlights the potential role that mental health education, and messages during training, may have in increasing help-seeking and self-care practices among workers.

Compassion, a core element of altruism can have both positive and negative impacts upon individual efficacy and longevity within such professions. Compassion fatigue, a potentially negative outcome of compassionate commitment, increases financial costs to organisations due to increases in sick leave, turnover (White 2006) and lower worker morale and productivity; all of which are indicative of burnout (Stamm et al. 2002). On the other hand, individuals who experience compassion satisfaction, are less likely to experience symptoms of burnout as the individual feels as though they are performing their job competently and have the right social supports in place to do so (Stamm 2002). As Maslach (1982) highlights, burnout is not a problem of people, but rather the environment in which people work. Therefore, in order to decrease such negative perceptions of individual help-seeking observed in the current sample, it may be useful to look at ways to foster work and training environments that encourage compassion satisfaction rather than fatigue.

Despite finding low current help-seeking behaviour in this sample, participants perceived they would be more likely to seek help when in the field. Such future intentions to seek help may be explained by trainee recognition that proactive help-seeking in an occupational context would be an appropriate and likely beneficial response. Whilst these findings may reflect demand characteristics, it is notable that several participants indicated that formal help-seeking (i.e. health professionals or within the organisation) would be warranted given their understanding of specific mental health risks associated with aid work. Future research could test this relationship to determine whether perceived assistance needs of field workers are acted upon (and the circumstances that make this "acceptable"), or whether they are consistent with non-occupational contexts where help is often avoided or negated (Mackenzie et al. 2006). Therefore, although participants reported that help-seeking in their current lives is limited due to such things as not wanting to be a burden, it appears that with increased field-based mental health literacy, help-seeking with future colleagues may be seen as more acceptable. Thus, the implementation of training that further fosters this way of thinking may build upon worker resilience in the field. Help-seeking and its relationship with mental health remains an underrepresented area in the HA literature. Research is needed to better understand both the attitudes and behavioural skills that allow workers to successfully elicit appropriate support when needed, and potential restraints such as altruistic self-image and perceived stigma. Such research could examine the development of help-seeking intentions, and whether greater mental health literacy (e.g. Mental Health First Aid training), including symptom recognition and assistance "thresholds", can change access rates to formal and informal sources of support.

A reflexive approach was maintained throughout the research process. That is, whilst care was taken to ensure representativeness and validity of the identified themes, the researcher assumes an active role in the interpretative process (Braun and Clarke 2006). As such, it is recognised that context, knowledge and beliefs play a role in the extraction of themes from the data and thus are shaped by researcher reflexivity. This is not a limitation of the current study as the results and subsequent interpretations were grounded in the data and further justified through the use of a co-rater. The use of an independent co-rater ensured the dependability of findings through establishing inter-rater reliability and also increased the credibility of findings as all themes were confirmed via the inter-rater process (Golafshani 2003).

As the present study employed a purposive sample within a qualitative study, the findings cannot be generalised further than the sample employed in the analysis. The study also focused on an undergraduate university sample and, as such, its findings are most relevant to this HA trainee sub-population. Whilst purposive sampling of students from one university may also restrict the transferability of findings, subsequent research may employ the same methodology on samples from other institutions at similar stages in training. Such re-testing may provide further confirmation of the present findings.

\section{Conclusion}

The findings from the present study are important insofar as they provide a preliminary insight into the potential risk and resilience factors present in trainee HA workers. The major findings indicate two areas of resilience and one area of risk within this population. Social support based on likeness, and the evolving ideas of HA work indicate flexibility within the current population through the reported ability to adapt to new physical, 
emotional and social environments. Conversely, the contradictory nature of help-seeking indicates an area of potential risk. The reported lack of help-seeking in the context of high personal stress warrants further research attention, as a failure to seek help has been linked to increased mental health problems in the general population (Rickwood et al. 2007), and may similarly mediate mental health outcomes among HA workers. Recent occupational health literature suggests a pathway from such risk factors to occupational burnout and to conditions such as depression and PTSD (Brooks et al. 2015; Musa and Hamid 2008). Whilst factors such as coping style and poor social support are recognised contributors to burnout among HA workers (Brooks et al. 2015), the relationship between help-seeking and burnout has not been investigated in this population. Future research investigating this pathway, and the potential role of help-seeking attitudes and skills, may support important developments in training and self-care practices among these professionals. A follow-up study assessing the risk and resilience trajectories and how future training fosters such factors within the current sample is recommended as such information may be invaluable for future training programs.

\section{Abbreviations}

HA: Humanitarian aid; PTSD: Posttraumatic stress disorder

\section{Acknowledgements}

We would like to thank Lisa McKendry for independently co-rating the results of the present study.

\section{Availability of data and materials}

Data from the current study is stored in the Western Sydney University ResearchDirect research depository, which is available to fellow researchers with access available upon request to the principle author.

\section{Authors' contributions}

KS and GS conceived the idea and designed the study. KS carried out the data collection and transcribed the data. KS and GS interpreted the results and KS wrote the manuscript. KS, GS and MT revised the manuscript for important intellectual content. All authors read and approved the final manuscript.

\section{Funding}

Funding to reimburse participants for their time and travel was provided by the School of Social Sciences and Psychology at Western Sydney University.

\section{Ethics approval and consent to participate}

The study was approved by the Western Sydney University Human Research Ethics Committee (project number H11594).

All participants received information sheets and signed consent forms prior to participation.

\section{Consent for publication}

Consent for publication from each participant was obtained prior to commencement of data collection.

\section{Competing interests}

The authors declare that they have no competing interests.

\section{Publisher's Note}

Springer Nature remains neutral with regard to jurisdictional claims in published maps and institutional affiliations.

\section{Author details}

Humanitarian and Development Research Initiative (HADRI), School of Social Sciences and Psychology, Western Sydney University, Penrith, NSW 2751, Australia. ${ }^{2}$ Department of Psychology, Macquarie University, North Ryde, NSW 2109, Australia.

Received: 2 May 2017 Accepted: 24 October 2017

Published online: 09 November 2017

\section{References}

Aakre JM, Lucksted A, Browning-McNee LA (2016) Evaluation of youth mental health first aid USA: a program to assist young people in psychological distress. Psychol Serv 13:121

Ager A, Pasha E, Yu G, Duke T, Eriksson C, Cardozo BL (2012) Stress, mental health, and burnout in national humanitarian aid workers in gulu, northern Uganda. J Trauma Stress 25:713-720 718p. doi:10.1002/jts.21764

Armagan E, Engindeniz Z, Devay AO, Erdur B, Ozcakir A (2006) Frequency of post-traumatic stress disorder among relief force workers after the tsunami in Asia: do rescuers become victims? Prehosp Disaster Med 21:168-172

Barsalou J (2008) Trauma and transitional justice in divided societies. Washington DC: DIANE Publishing; p 2008

Benkel I, Wijk H, Molander U (2009) Family and friends provide most social support for the bereaved. Palliat Med 23:141-149. doi:10.1177/0269216308096797

Braun V, Clarke V (2006) Using thematic analysis in psychology. Qual Res Psychol 3:77-101

Brooks SK, Dunn R, Sage CAM, Amlôt R, Greenberg N, Rubin GJ (2015) Risk and resilience factors affecting the psychological wellbeing of individuals deployed in humanitarian relief roles after a disaster. J Ment Health 24:385-413. doi:10.3109/09638237.2015.1057334

Burke KJ, Shakespeare-Finch J (2011) Markers of resilience in new police officers: appraisal of potentially traumatizing events. Traumatology 17:52-60. doi:10.1177/1534765611430725

Cardozo BL, Crawford CG, Eriksson C, Zhu J, Sabin M, Ager A et al (2012) Psychological distress, depression, anxiety, and burnout among international humanitarian aid workers: a longitudinal study. PLoS One 7:9

Cardozo BL, Holtz TH, Kaiser R, Gotway CA, Ghitis F, Toomey E, Salama P (2005) The mental health of expatriate and Kosovar Albanian humanitarian aid workers. Disasters 29:152-170

Chan JBL, Devery C, Doran S (2003) Fair cop: learning the art of policing: University of Toronto Press

Comoretto A, Crichton N, Albery I (2015) Resilience in humanitarian aid workers: understanding processes of development. IIE Trans Occup Ergon Human Factors 3:197-209

Connorton E, Perry MJ, Hemenway D, Miller M (2012) Humanitarian relief workers and trauma-related mental illness. Epidemiol Rev 34:145-155

Cooke R, French DP (2008) How well do the theory of reasoned action and theory of planned behaviour predict intentions and attendance at screening programmes? Metaanal Psychol Health 23(7):745-765

Cooper J, Metcalf O, Phelps A (2014) PTSD-an update for general practitioners. Aust Fam Physician 43:754

Dahlgren AL, DeRoo L, Avril J, Bise G, Loutan L (2009) Health risks and risk-taking behaviors among International Committee of the red Cross (ICRC) expatriates returning from humanitarian missions. J Travel Med 16:382-390

Defence Health. (2016). Post-traumatic stress disorder [health portal]. Retrieved from http://www.defence.gov.au/health/healthportal/PTSD.asp

Delgatty CR (2011) Evaluating the effectiveness of short-term humanitarian aid. Doctoral dissertation, Texas State University-San Marcos

Derogatis LR, Lipman RS, Rickels K, Uhlenhuth EH, Covi L (1974) The Hopkins symptom checklist (HSCL): a self-report symptom inventory. Syst Res Behav Sci 19:1-15

Ehrenreich JH, Elliott TL (2004) Managing stress in humanitarian aid workers: a survey of humanitarian aid agencies' psychosocial training and support of staff. Peace Confl J Peace Psychol:1053-1066. doi:10.1207/s15327949pac1001_4

Eriksson CB, Cardozo BL, Foy DW, Sabin M, Ager A, Snider L et al (2012) Predeployment mental health and trauma exposure of expatriate humanitarian aid workers: risk and resilience factors. Traumatology. 19(1):41-48. doi:10.1177/ 1534765612441978

Eriksson, CB, Bjorck JP, Larson LC, Walling SM, Trice GA, Fawcett J, Foy DW (2009) Social support, organisational support, and religious support in relation to burnout in expatriate humanitarian aid workers. Ment. Health Rel. Cult. 12(7): 671-686. doi:10.1080/13674670903029146. 
Eriksson CB, Kemp HV, Gorsuch R, Hoke S, Foy DW (2001) Trauma exposure and PTSD symptoms in international relief and development personnel. J Trauma Stress 14:205-212

Fereday J, Muir-Cochrane E (2006) Demonstrating rigor using thematic analysis: A hybrid approach of inductive and deductive coding and theme development. Int. J of Qual Methods, 5(1):80-92. doi:10.1177/ 160940690600500107

Fischer EH, Turner JL (1970) 'Orientations to seeking professional help: development and research utility of an attitude Scale': erratum. J Consult Clin Psychol 35:375-375. doi:10.1037/h0020198

Gist, R., \& Woodall, S. J. (2000). There are no simple solutions to complex problems

Golafshani N (2003) Understanding reliability and validity in qualitative research. Qual Rep 8:597-606

Gourash N (1978) Help-seeking: a review of the literature. Am J Community Psychol 6:(5)413-423. doi:10.1007/bf00941418

Gulliver A, Griffiths KM, Christensen H (2010) Perceived barriers and facilitators to mental health help-seeking in young people: a systematic review. BMC psychiatry 10:113

Hobfoll, S. E. (1988). The ecology of stress: Taylor \& Francis

Humanitarian Outcomes. (2016). Aid worker security report; figures at a glance [Pdf report]. Retrieved from https://aidworkersecurity.org/sites/default/files/ HO_AidWorkerSecPreview_1015_G.PDF_.pdf

Jensen KB, Morthorst BR, Vendsborg PB, Hjorthoj C, Nordentoft M (2016) Effectiveness of mental health first aid training in Denmark: a randomized trial in waitlist design. Soc Psychiatry Psychiatr Epidemiol 51:597-606. doi:10.1007/s00127-016-1176-9

King LA, King DW, Leskin G, Foy DW (1995) The Los Angeles symptom checklist a self report measure of posttraumatic stress disorder. Assessment 2:1-17

Kitchener BA, Jorm AF (2004) Mental health first aid training in a workplace setting: a randomized controlled trial [ISRCTN13249129]. BMC Psychiatry 4:23

Lee ACK (2008) Local perspectives on humanitarian aid in Sri Lanka after the tsunami. Public Health 122:1410-1417

Mackenzie CS, Gekoski WL, Knox VJ (2006) Age, gender, and the underutilization of mental health services: the influence of help-seeking attitudes. Aging Ment Health 10:574-582

Maslach C (1982) Burnout: the cost of caring. Malor Books, Cambridge MA

McCammon S, Durham TW, Allison Jr EJ, \& Williamson JE (1988) Emergency workers' cognitive appraisal and coping with traumatic events. J. Trauma. Stress. 1(3):353-372. doi:10.1007/BF00974770.

McCall M, Salama P (1999) Selection, training, and support of relief workers: an occupational health issue. Br Med J 318:113

Metcalfe V, Martin E, Pantuliano S (2011) Risk in humanitarian action: towards a common approach. HPG commissioned paper. ODI, London

Mollica RF, Cardozo BL, Osofsky HJ, Raphael B, Ager A, Salama P (2004) Mental health in complex emergencies. Lancet 364:2058-2067

Moreno-Jiménez MP, Villodres MCH (2010) Prediction of burnout in volunteers. J Appl Soc Psychol:401798-401818. doi:10.1111/j.1559-1816.2010.00640.x

Morse JM (1995) The significance of saturation. Qual. Health Res. 5(3):147-149.

Musa SA, Hamid AARM (2008) Psychological problems among aid workers operating in Darfur. Soc Behav Pers 36:407-416. doi:10.2224/sbp.2008.36.3.407

O'Connell ME, Boat T, Warner KE (2009) Preventing mental, emotional, and behavioral disorders among young people: progress and possibilities: National Academies Press

Putman KM, Lantz Jl, Townsend CL, Gallegos AM, Potts AA, Roberts RC et al (2009) Exposure to violence, support needs, adjustment, and motivators among Guatemalan humanitarian aid workers. Am J Community Psychol 44:109-115. doi:10.1007/s10464-009-9249-5

Quevillon RP, Gray BL, Erickson SE, Gonzalez ED, Jacobs GA (2016) Helping the helpers: assisting staff and volunteer workers before, during, and after disaster relief operations. J Clin Psychol. 72(12):1348-1363. doi:10.1002/jclp. 22336

Rickwood DJ, Deane FP, Wilson CJ (2007) When and how do young people seek professional help for mental health problems. Med J Aust 187:35-\$39

Robinson R (1993) Follow-up study of health and stress in ambulance services, Victoria, Australia. Victorian Ambulance Crisis Counselling Unit, Victoria

Rose SC, Bisson J, Churchill R, Wessely S (2002) Psychological debriefing for preventing post traumatic stress disorder (PTSD). Cochrane Libr. doi:10.1002/ 14651858.CD000560

Salama P, Buzard N, Spiegel P (2001) Improving standards in international humanitarian response: the sphere project and beyond. JAMA 286:531-532
Sandelowski M (1995) Sample size in qualitative research. Res. Nurs. Health.18(2): 179-183. doi:10.1002/nur.4770180211.

Shuler S, Sypher BD (2000) Seeking emotional labor: when managing the heart enhances the work experience. Manag Commun Q 14:50-89

Stamm BH (2002) Measuring compassion satisfaction as well as fatigue: developmental history of the compassion satisfaction and fatigue test. In: Figley CR (ed) Treating compassion fatigue. Brunner/Rutledge, New York, pp 107-119

Stamm BH, Varra EM, Pearlman LA, Giller E (2002) The helper's power to heal and to be hurt-or helped-by trying. Register Report: A Publication of the National Register of Health Service Providers in Psychology, Washington, DC

Staniford AK, Dollard MF, Guerin B (2009) Stress and help-seeking for droughtstricken citrus growers in the Riverland of South Australia. Aust J Rural Health 17(147-154):148p. doi:10.1111/j.1440-1584.2009.01059.x

Tassell NA (2009) Motivation and well-being in humanitarian health workers: relating self-determination theory to hedonic vs eudaimonic well-being, vitality and burnout: a thesis presented in partial fulfilment of the requirements for the degree of doctor of philosophy in psychology. Massey University, Palmerston North

Thirlaway K, Upton D (2009) The psychology of lifestyle: promoting healthy behaviour: Routledge

Thoits PA (2011) Mechanisms linking social ties and support to physical and mental health. J Health Soc Behav 52:145-161

Van der Kolk BA, Fisler R (1995) Dissociation and the fragmentary nature of traumatic memories: overview and exploratory study. J Trauma Stress 8:505-525

Wanous JP, Poland TD, Premack SL, Davis KS (1992) The effects of met expectations on newcomer attitudes and behaviors: a review and meta-analysis. J Appl Psychol 77:288

White, R. A. (2006). Perceived stressors, coping strategies, and burnout pertaining to psychiatric nurses working on locked psychiatric units

Whittlesey V (2001) Diversity acitivites for psychology. Needham Heights, MA, US: Allyn \& Bacon

Zuckerman M, Gagne M (2003) The COPE revised: Proposing a 5-factor model of coping strategies. J. Res. Pers. 37(3):169-204. doi:10.1016/S00926566(02)00563-9.

Zartaloudi A, Madianos MG (2010) Mental health treatment fearfulness and help-seeking. Issues Ment Health Nurs 31:662-669 668p. doi:10.3109/ 01612840.2010 .490929

Zhen Y, Huang Z, Jin J, Deng X, Zhang L, Wang J (2012) Posttraumatic stress disorder of red cross nurses in the aftermath of the 2008 Wenchuan China earthquake. Arch Psychiatr Nurs 26:63-70. doi:10.1016/j.apnu.2011.02.004

Zimet GD, Dahlem NW, Zimet SG, Farley GK (1988) The multidimensional scale of perceived social support. J. Personal. Assess. 52(1):30-41. doi:10.1207/ s15327752jpa5201_2

\section{Submit your manuscript to a SpringerOpen ${ }^{\mathcal{O}}$ journal and benefit from:}

- Convenient online submission

- Rigorous peer review

- Open access: articles freely available online

- High visibility within the field

- Retaining the copyright to your article

Submit your next manuscript at springeropen.com 